\title{
Article
}

\section{Transforming Rehabilitation and its impact on a locally-based rehabilitation programme for Black and Minority Ethnic and Muslim offenders}

Hough, Christine Victoria

Available at http://clok.uclan.ac.uk/15062/

Hough, Christine Victoria (2016) Transforming Rehabilitation and its impact on a locally-based rehabilitation programme for Black and Minority Ethnic and Muslim offenders. European Journal of Probation, 8 (2). pp. 68-81.

It is advisable to refer to the publisher's version if you intend to cite from the work. http://dx.doi.org/10.1177/2066220316660433

For more information about UCLan's research in this area go to http://www.uclan.ac.uk/researchgroups/ and search for <name of research Group>.

For information about Research generally at UCLan please go to http://www.uclan.ac.uk/research/

All outputs in CLoK are protected by Intellectual Property Rights law, including Copyright law. Copyright, IPR and Moral Rights for the works on this site are retained by the individual authors and/or other copyright owners. Terms and conditions for use of this material are defined in the policies page. 


\title{
Transforming Rehabilitation and its impact on a locally-based rehabilitation programme for BAME
} and Muslim offenders.

\begin{abstract}
.
This paper discusses the outcomes of a proposed evaluation of an offender rehabilitation programme called ReachingOut, which operates in North West England and is tailored to the needs of Black and Minority Ethnic (BAME) and Muslim offenders. The start of the evaluation coincided with the major restructuring of the probation services in England and Wales, as part of the Transforming Rehabilitation (TR) agenda. Six months into the evaluation, no primary research data had been made available for the evaluation. This paper discusses the events that conspired to thwart the evaluation and analyses critically the policies underpinning TR, with reference to the literature and continuing neo-liberal governmental approaches to cost cutting across public services.
\end{abstract}

Keywords: Rehabilitation; Muslim; desistance; third sector; managerialisation; payment by results.

\section{Backgound to the evaluation.}

The evaluation of ReachingOut, an offender rehabilitation model tailored specifically to the needs of Black and Minority Ethnic (BAME) and Muslim offenders, was originally conceived as a smallscale qualitative research project. Arooj, a Third Sector Organisation (TSO) has delivered this model over the last eight years through HM prisons and communities in North West England. Arooj's rehabilitation work was initially funded, several years ago, by a grant from a private charitable trust. When this funding was spent, Arooj continued to provide their services to HM Prisons on a purely voluntary basis. In 2014 we bid (successfully) for funding to support the evaluation of ReachingOut, from our local Probation Trust (now part of the regional Community Rehabilitation Company) and the National Offender Management Services. 
The evaluation was designed to collect data from between eight to ten BAME and Muslim offender respondents who would be referred, by offender managers, to Arooj. This data would be analysed to ascertain the offenders' perceptions of their individual journeys towards rehabilitation, reintegration and desistance from re-offending. The findings from the analysis of the data would provide a critical evaluation of the extent to which Arooj's clients were able/unable to sustain their progress towards rehabilitation, reintegration and desistance from re-offending after release from prison, over a period of twelve months. Originally, we had hoped to collect the data through focus group discussions that would take place at different stages of the respondents' rehabilitation journeys and a small number of loosely structured interviews. The data was to be analysed using analytic tools based on Carol Gilligan's Listening Guide (Brown and Gilligan, 1991; Keiglemann, 2009; Ribbens and Edwards, 1998) and selected tools from grounded theory (Glaser and Strauss, 2007).

The inspiration for the evaluation evolved from discussions I had had with Arooj about the nature of their rehabilitation model and how this might fit into the new landscape of Transforming Rehabilitation (TR) within the framework of the Community Rehabilitation Companies (CRCs), now run under contract by corporate organisations rather than Probation Trusts. Arooj's mentoring work had gathered momentum over recent years in local HM prisons throughout the North West, because of the rising numbers of BAME and Muslim offenders within the prison population. Recent research shows (Prison Reform Trust, 2013; Mullen, 2014; HMG 2015) that people from Black and Minority Ethnic (BAME) communities are over-represented at almost all stages of the Criminal Justice process and that BAME and Muslim prisoners on the inside continue to have a worse experience than the rest of the prison population. This is evidenced through the following statistics:

- $14 \%$ of Prisoners are Muslim compared to only $4 \%$ in the National Population. 
- $16 \%$ of the British national prison population are Black and Asian (10\% Black and 10\% Asian). For black Britons this is significantly higher than the $2.8 \%$ of the general population they represent.

- $\quad$ The number of Muslim prisoners has doubled since 2002

(Prison Reform Trust, 2015).

This upward trend in the Muslim prison population prompted Arooj, to conduct their own survey of BAME and Muslim ex-offenders (Mahmood and Mohammad, 2014, not published) in their region, to ask them what they considered to be the reasons that led them to offend; their experiences and views about the support services available; the consequences of their offending upon their family and community and the kind of help and support they needed in order for them not to re-offend. The responses to the survey (which comprised one hundred and fifty individuals) included: over $75 \%$ said they had lost respect with their family and community; $36 \%$ stated that specialist cultural and religious support would help them to stay out of trouble; $30 \%$ were involved in drug and alcohol abuse and $90 \%$ said the services they received were insufficient for their needs. This latter group of respondents went on to suggest that if befriending and mentoring support had been available to them inside prison - and particularly upon release - they would have accessed this to help them in their resettlement and rehabilitation back into their communities. These responses helped to shape the development of Arooj's own model of mentoring support for offenders and exoffenders (see below) and on this basis we felt that it would be a worth applying for the funding with which to conduct an evaluation of their support work. This was also important to the sustainability of Arooj's future work, because at this stage they were without funding to continue their work.

Having worked for a number of years with BAME and Muslim offenders and ex-offenders in local HM prisons and communities, Arooj was invited to contribute to the Young Report (Mullen, 2014) 
and sat on the Task Force that participated in a series of expert group meetings, consulting on issues such as commissioning, resettlement and the needs of Muslim prisoners. This recognition of Arooj's work in this area is timely but lends a certain irony to the fact that the intended evaluation of their support model was prevented by the very system they have supported through their rehabilitation work over the years. The content of the Young Report, chaired by Baroness Young of Hornsey, is the outcome of research undertaken by a Task Group, which ran from Autumn 2014 and was set up to advise the Ministry of Justice and future providers on how to improve outcomes for young black and/or Muslim men in the Criminal Justice System. One of the aims of the Report was to consider how the knowledge (based on research evidence) that black and Muslim male offenders experience disproportionately negative outcomes, both in prison and the community, may be applied in the significantly changed environment introduced under the Transforming Rehabilitation (TR) reforms. One of the recommendations from the Report is that 'rigorously monitored mechanisms need to be developed and implemented to ensure that independent providers address the specific needs of BAME offenders (Mullen, 2014, p. 13)'. This highlights one of the critical issues for discussion in this paper, that the needs of BAME and Muslim prisoners and exoffenders include some distinctive features that are not common across the general population of this group (see later in this paper).

\section{Arooj's model of rehabilitation support.}

Since its inception, Arooj has worked to provide mentoring support to help BAME and Muslim offenders in their resettlement and rehabilitation back into their communities, after release from prison. Their rehabilitation model is based on a model of mentoring and support that comprises three stages.

- $\quad$ Stage One, at which the mentors build and establish a trusting relationship with the offenders whilst they are in prison, in order to set in place lines of communication and support between them and their families. Arooj provides an impartial service that is 
independent of any part of the CJS system and is often the only Asian support group working in a prison. This factor is significant to their clients whose perception is that the Arooj mentors support them individually, rather than as part of the 'system' of rehabilitation and resettlement that operates inside prisons.

- $\quad$ At Stage Two of the model Arooj will refer their clients to multi-agency groups (such as drugs and alcohol support) for their health/mental needs; identify potential employment opportunities within their communities and intervene with their families to encourage their re-integration and acceptance back into the family network.

- $\quad$ Stage Three is lifelong and may endure indefinitely, for as long as the offender and their family require Arooj's support.

These are not discrete, or stand-alone stages of support but, together, are interdependent and comprise a holistic model of support and is this aspect of the model that Arooj considers to be the main contributory factor to its success. Through establishing the initial, trusting relationship with their clients at Stage One, Arooj are able to contact the offenders' families and support them, both practically and emotionally, through to Stage Two. The families of BAME, Muslim offenders often have difficulty in coming to terms with their own feelings towards their offending sibling/son/daughter because of the sense of dishonour that a criminal offence brings upon the family. Therefore the families come to regard Arooj as trustworthy confidantes to whom they can talk freely because they share the same culture and faith. Throughout Stage Two Arooj works towards building bridges between the offenders and their families in order to facilitate support for them 'through the gate' and after. The involvement of BAME ex-offenders' families in the rehabilitation process is another crucial factor in the overall success of Arooj's three stage model of support, which is predicated on the notions of inclusion and social justice. The first two stages address the specific needs of offenders and their families in their rehabilitation and resettlement processes. In the transition from stage two, to three and thereafter Arooj help to empower offenders 
in making the significant step from the 'transformative issues of welfare provision, such as individual need, diagnosis and rehabilitation' (Clarke et al. (2000, p. 178) to becoming independent individuals who are able to access the resources associated with social justice, such as their social and family networks, employment, housing and the means to live independently. Arooj have the capacity to facilitate this final element by drawing on their own contacts within their community, to source employment opportunities and help clients to re-establish their family and social networks. Viewed together, the different stages of this model of rehabilitation bear a similarity to the 'ethical entitlement' of probation service support discussed by Burke (2012, p.5), who says that 'supporting and helping individuals towards achieving a better life and treating them with humanity is an ethical entitlement and not one contingent upon reducing reoffending at .....the lowest possible cost'. Frazer et al (2014, p.94) express their concerns about the danger that the government's Transforming Rehabilitation (TR) agenda might be implemented 'at the expense of good services for the offender population as a whole' and, certainly, the outcomes of ReachingOut so far supports this view. If the new CRCs are forced to follow the contingency of 'best for least' this will very likely serve to reduce ex-offenders' 'ethical entitlement' of support in achieving a 'better life', to that of short term rehabilitation programmes that are designed solely to meet the basic targets for reducing re-offending under the new TR arrangements (which are discussed in more detail later on).

\section{The specific needs of BAME, Muslim offenders and their families.}

The needs that are commonly attributed to white, working class offenders differ from those of BAME and Muslim offenders. A distinctive feature of Arooj's rehabilitation work with this cohort of offenders is their capacity to meet their specific needs because they are representative of the BAME and Muslim community and they work independently of the Criminal Justice System (CJS). The factors that contribute to the profile of the wider prison population include: 'broken homes; drug and alcohol misuse; generational worklessness; abusive relationships; childhoods spent in 
care; mental illness and educational failure' (MOJ 2013. p.5). Whilst there will inevitably be some overlap, the needs of BAME, Muslim offenders differ in several respects from those of the wider population of offenders. In the responses to Arooj's survey, (Mahmood and Mohammad, 2014), $36 \%$ of the respondents stated that 'specialist cultural and religious support would help them to stay out of trouble' (p.7). This, and the high proportion of respondents who said that they felt they had lost respect with their family and community (mentioned earlier) are areas of need that are specific to BAME and Muslim offenders/ex-offenders. The wider discourse of the needs of different minority ethnic groups of offenders are explored at length in Adam Calverley's book Cultures of Desistance (2013) and include factors such as the importance of cultural, family and religious values to ex-offenders to supporting them in their journey towards desistance from re-offending. There is an absence of any clear acknowledgement of the diversity of needs across different groups of offenders in the original Transforming Rehabilitation proposal (MoJ, 2013) and this is cited as a shortcoming by Anning et al $(2014$, p.13) because 'offenders are presented within Transforming Rehabilitation as a homogenous group... and there is little acknowledgement of their diversity'. Frazer et al. (2014, p.93) argue this further, within the context of the cost cutting and cutbacks that preceded and continued after, the awarding of CRC contracts to the new corporate owners: 'if quality services are not safeguarded within the commissioning process.....deeper understanding of offenders' needs and of the desistance process itself will be lost in a one size fits all approach to offender supervision'. Here the authors foresee the potentially adverse outcomes of TR if the specialist local services of the TSOs are not retained by the new CRCs. Indeed, the $2014-2015$ annual report of Her Majesty's Inspector of Prisons (HMIP) (HMG, 2015) indicates that this has already been the case on the inside (of prisons) as a direct result of the TR agenda '....Staff shortages and uncertainty about the future [TR] model meant many prisoners did not receive sufficient support for their resettlement back into the community or to reduce the risk that they would reoffend' (ibid. p. 57). 


\section{Transforming Rehabilitation (TR) and changes to the probation services.}

A former local Probation Trust, now the regional CRC, part-funded the evaluation of ReachingOut and it was agreed that Arooj would be attached to the CRC in order for offender managers to make referrals of BAME and Muslim offenders directly to Arooj; these clients would be the participants in the evaluation. At the time of making these arrangement, (late 2014), the CRC itself was experiencing the structural changes that were taking place across the probation services nationally, as part of the TR agenda. From January 2013, the coalition government had set in train the fastpaced changes that re-structured the former Probation Trusts into CRCs, followed by the final, step change that transferred the CRCs 'from public to private, voluntary or social sector ownership' (NOMS 2014, p.22). These significant changes to the way low-medium risk offenders are to be managed under the new TR arrangements are the outcomes of the coalition government's '....approach to driving down the rate of reoffending and delivering better value for the taxpayer', (MoJ 2013 p.3). The Offender Rehabilitation Act (ORA) is the Act of Parliament (Her Majesty's Government, 2014) that accompanied the Transforming Rehabilitation programme and it made changes to the sentencing and releasing (of offenders) framework, to extend 'statutory monitoring and supervision to offenders serving short term custodial sentences for a mandatory period of up to 12 months' (Clinks, 2015 p.1). The role of the newly privatised CRCs is to provide this statutory probationary supervision through community-based offender management and rehabilitation services, to those ex-offenders who are assessed as low-medium risk. Those offenders categorized as presenting a 'high risk of serious harm... will continue to be supervised by a publicly managed but newly- constituted (and smaller) National Probation Service (NPS)' (Ludlow, 2014, p. 67).

The National Offender Management Services (NOMS) agency was responsible for overseeing the implementation of the TR agenda and also the competitive tendering process, which led to the application of 'contract mechanisms' (Ludlow (2014, p. 68) to the management of the newlystructured probation services. The successful bidders for the twenty one CRC contracts, throughout 
England and Wales, are described as 'global security corporations' by Fitzgibbon and Lea (2014 p. 24) and they include: Sodexo, A4E and Ingeus amongst others, whose expertise is mostly in the outsourcing of public services, rather than front line delivery of resettlement and rehabilitation support services to ex-offenders. A requirement of the competitive bidding process was for these corporations to set up joint ventures with social enterprise groups, charities and similar voluntary and community organisations. These collaborations were exhorted by Chris Grayling, the former Minister of Justice, who emphasised that 'It will be crucial that providers work closely with all local partners to ensure that the service delivered to achieve the reducing reoffending outcomes are aligned with other local services' (MoJ 2013, p.14). Frazer et al (2014) argue that:

'good rehabilitation can only be achieved if the CRC's supply chain and its own commissioning activity can identify and harness local interventions...that will respond effectively to [offenders'] needs and issues.... and help them forge a new, non-criminal identity’ (Frazer et al 2014, p.101).

This reaffirms the importance of local, TSO organisations to the process of effective rehabilitation and resettlement, something that is reflected in Arooj's own mission statement, which has at its core the aim of supporting 'the re-entry, resettlement and re-integration of BAME Ex-offenders back into society' (Arooj 2014, p.11). The failure of the TR system, in the form of the regional CRC, to incorporate Arooj's rehabilitation services effectively into their regional programme for reducing reoffending is one example of the dissonance between the rhetoric of government policy (see the Grayling quote above) and the reality of its implementation. The competitive bid process for TR has resulted in the 'carve up' of the probation services in England and Wales in which they were sold to the highest (or lowest) bidders. Fitzgibbon and Lea (2014, p. 29) discuss the danger that these changes will make 'traditional probation and voluntary sector skills a distant memory' that will make 'risk management and security strategy' dominate over the more traditional, valuesbased skills sets that characterised the original probation services. The eclipsing of the traditional 
partnership between probation and TSOs by a quantitative, target driven approach to rehabilitation is inevitable under the new payment by results $(\mathrm{PbR})$ system, which Fitzgibbon and Lea describe as the 'death knell of TSOs' (ibid, p.32).

\section{Payment by Results (PbR)}

Payment by Results $(\mathrm{PbR})$, the system of payment for the new CRCs, is not a new concept. It was introduced as a policy into the education system in nineteenth century Britain with the intention to 'bring schools and teachers under the 'laws of supply and demand' (Jabbar 2014, p.220). Jabbar describes the (unintended) outcomes of the policy, as ultimately leading to 'the narrowing of the curriculum, cheating and manipulation by schoolteachers and managers, and increased risk and uncertainty in the teaching profession'. These negative outcomes/unintended consequences of a performance based management system, in place over a hundred years ago, arose from the 'overpressure on teachers to perform, leading to cheating and uncertainty' (ibid. p. 237). There are similarities between these outcomes and the evidence emerging from the early days of the implementation of the TR agenda. The PbR payment system for the CRCs enshrines all the characteristics of managerialisation, the process by which the public sector has been continually reformed across successive governments since the late 1970's/early 1980's. Cost cutting, in the form of paring back the resources and outgoings associated with the provision of expensive (in terms of manpower) casework-based probation services, is very likely to be the first priority of the CRCs, in order to meet their prescribed targets for reducing re-offending at the least cost - or achieving the greatest economy. Thus one of the ultimate outcomes of the TR agenda may well result in TSOs being absorbed into the new, marketised services for reducing reoffending to the 
extent that they will find themselves curtailing or 'reforming their own advocacy roles and functions in order to facilitate their involvement' within the CRC structure (Corcoran and Hucklesbury, 2012, p.3). This potential erosion of the role of TSOs, as part of the new corporate structure of the CRCs, is discussed more fully in the Discussion section later on.

There is evidence that the $\mathrm{PbR}$ payment system that underpins the TR arrangements is already forcing CRCs to focus on cost cutting in order to produce the most financial benefit, or profit. This leveraging of resources, or securing a 'bigger bang for the buck' (Hamel G, Prahalad, 1993, p. 75), could inevitably squeeze out many of the smaller TSOs from the new, corporate model of offender rehabilitation, because they will find themselves competing with the larger charitable organisations for contracts from the CRCs. This discouraging picture is reflected in the findings from a recent survey conducted by Clinks, (2015) in which Third Sector organisations were asked to provide responses to questions about how the TR agenda was affecting their own future prospects. The responses included:

'We see the contracts from CRCs as being very restrictive, if we were to take on said contract we would be forced to change our service to fit the contract, something which we firmly believe will have a lesser impact on offenders in the long run' (ibid. p. 7); 'Transforming Rehabilitation... has left the work we were funded to do in a state of limbo. [Our contract has] been extended for six months, with no guarantees of how we go forward' (ibid. p. 6).

Although these are early days, the outcomes of ReachingOut do not paint a very promising picture for Third Sector Organisations in the new world of TR. CRCs are in the process of restructuring their services and this has already involved the termination of existing contracts, certainly for the smaller TSOs, and making redundancies amongst the probation officer workforce they inherited from the former Probation Trusts. This latter issue has been taken up vigorously by the General 
Secretary of the National Association of Probation Officers and at a recent national conference he said:

'And job security is a huge issue, believe it or not, in the face of all the vacancies that are out there. Some CRCs are still struggling to recruit staff. Others such as those owned by Sodexo, as we have seen recently, have already made significant staff reductions'.... (Lawrence, 2015, p. 2).

As a small charity in the third sector, Arooj has the advantage of able to work independently of centrally imposed systems and processes and so is able to focus on the more values-based issues such as strengthening, or mending, the relationships between offenders and their families and helping to restore their clients' self-confidence after prison. Arooj is a BAME-led organisation and the work they do reflects the background, beliefs and culture of the community they serve. This aspect is given a high priority in the Young Review (Mullen 2014), where Baroness Young makes it clear, in her introduction, that mostly the criminal justice system 'does not represent the diverse backgrounds of offenders' and the involvement of 'representatives from the offenders' own communities and faiths can play a substantial role in improving...confidence in decision making processes and other procedures' (ibid. p. 12). This reflects exactly the role that Arooj has with their clients and their families.

\section{The outcomes of the evaluation.}

The outcomes of our attempts to conduct an evaluation of the ReachingOut programme made for difficult reading as I began to write up the progress we had made since the start. During the first six months no BAME, Muslim offenders were referred to Arooj by offender managers and therefore we were unable to recruit any research respondents or collect any primary data. As a consequence there has been no evaluation of Arooj's model of offender rehabilitation. This is a significant disappointment because an independent evaluation of Arooj's rehabilitation work within HM 
prisons and BAME and Muslim communities might have provided an endorsement for their services that could be used to promote their rehabilitation model to a wider audience that might include: service providers and Criminal Justice Systems in Europe and overseas, as well as the new CRCs in the UK.

\section{Findings and Discussions.}

\section{Impact of the Payment by Results system.}

From June 2015, the new contract holders/owners of the CRCs throughout England and Wales will be paid through the Payment by Results system. They will be dependent, to a large part, on meeting the quantitative targets and outcomes, set by the MoJ, to show that they are reducing 're-offending rates significantly beyond historic levels' (MoJ 2013c p.7). To be eligible for the PbR bonus payments, providers will need to show: 'both an agreed reduction in the number of offenders who go on to commit further offences and a reduction in the number of further offences committed by the cohort of offenders for which they are responsible' (ibid. p.15). The former is described as the frequency metric that 'measures the rate of offences committed by ex-offenders within a cohort within a 12 month period' after release; the latter is described as the 'binary metric' that measures the 'percentage of offenders that are convicted of an offence within a 12 month period' (ibid. p.8). ' $\mathrm{PbR}$ payments will be allocated on the basis of performance against the binary measure and the frequency measure, with a percentage of the total funding available linked to each' (MOJ, 2013b p.

8). This means that providers will 'only be paid for frequency reductions as long as the binary reoffending rate at least stays constant and does not increase' [over twelve months] (Frazer et al, 2014, p.97). Frazer et al argue that this requirement for adherence to the binary measure is in danger of encouraging the new providers to concentrate on ensuring a reduction in reoffending across this 'relatively short period of time', instead of 'supporting the more complex and uneven 
[and longer term] processes of secondary desistance' (ibid. p.98). This raises the question of whether the $\mathrm{PbR}$ system based on a 'pass/fail' performance metric is the most effective approach to supporting ex-offenders in the processes of rehabilitation and desistance from re-offending. An exoffender's journey towards desistance can be prey to the influence of many factors that are complex and intangible, such as the psycho-social aspects of an ex-offender's behaviour and their often chaotic, personal circumstances. Research findings emphasise 'the role of the individual agent in the desistance process' (King, 2013, p. 142) and so an individual's willpower to desist/not desist is also a significant consideration. These types of influences are very difficult to quantify, or measure, because they are linked intrinsically to an individual's own agency, or motivation and are, perforce, closely aligned to their personal values and beliefs. Frazer et al (2014 p. 96) describe the process of rehabilitation as increasingly ' ... a complex process that can support or hamper, but cannot command or compel'. This is a useful context within which to explain the value of the advocacy support that Arooj provides. As mentors they support ex-offenders through a medium of trust, rather than through threat or coercion. Therefore their clients work with them on a voluntary basis and this is one of the reasons for Arooj's past successes; their clients are encouraged to want to desist from re-offending and are supported individually at all stages of the rehabilitation journey. Such an approach is expensive in terms of time and resources, so is likely to prove incompatible with the PbR regime of cost-cutting, value-for-money and meeting targets within a specific timeframe. Under the PbR system success will be determined by whether the CRCs achieve a quantifiable measure of reductions in reoffending within a specified timeframe, rather than addressing the reasons why clients reoffend. This focus on measurable outcomes, rather than addressing the more complex aspects of clients' individual needs was apparent in the regional, pilot partnership that Arooj was attached to, evidenced through the reduction of their three stage model of support to one. 


\section{Primary and secondary desistance.}

King (2013, p.137) describes primary desistance as 'a crime-free gap or lull in offending', (which occurs in the time immediately after release from prison) and secondary desistance as involving 'the assumption of a non-offender identity'. Secondary desistance is a longer term process than primary desistance and is more 'complex and uneven', Frazer et al (2014, p. 98). The historic successes of Arooj's model of rehabilitation can be attributed to the fact that they address both processes of desistance, primary and secondary. They help clients through the early stages, on the inside and 'through the gate', and then in the longer term through their intervention with families and multi-agency support groups, advice and guidance about securing employment on a selfemployed basis and through their contacts within the wider community that very often lead to employment opportunities. According to Fitzgibbon and Lea, (2014, p. 33) the PbR system is in danger of providing 'an incentive, on the part of all concerned, to fail to report breaches and reoffending' because the corporate providers are likely to view the process of making significant reductions in reoffending as 'a high-stakes gamble on which they will be loath to risk 'large amounts of money'. In other words providers will not risk the expense of running those programmes of rehabilitation and support that do not guarantee the bonus payment. Therefore, support for secondary desistance may prove too much of a financial risk and the CRC providers may focus all their attention on the shorter term, primary desistance programmes, which are unlikely to be sustainable in the longer term.

\section{Erosion of the role of TSOs under the TR arrangements.}

Fitzgibbon and Lea (2014, p. 32) see the opening up of the probation services to a mix of providers as the 'death knell' to TSOs and the TR structure as the 'vehicle of.....homicide', wherein the 'security-industrial complex and voluntary sector will openly compete for funding'. They foresee these new alliances as the harbingers of the erosion of the traditional role of TSOs, which is one of independent, non-judgemental advocacy. In the new world of TR and the marketization of the 
probation services (through corporate ownership of the CRCs) the traditional role of the TSOs is in danger of being 'subsumed within a range of actuarial techniques of classification, risk assessment and resource management' (Clarke et al. p. 178), which characterise the business-based model of the new corporate contract holders. In contrast, the work of voluntary groups such as Arooj has historically focused on the more 'transformative issues such as individual need, diagnosis and rehabilitation' (ibid.). But there is a real danger that, far from harnessing 'local interventions...that will respond effectively to [offenders'] needs and issues' (Frazer et al 2014, p.101), the TR agenda may serve to reduce even further the likelihood of any commonality between the vision and aims of TSOs and those of the CRCs's. 'Since the 1980s, successive governments have seen contractual mechanisms.... as a route to more efficient and effective public services' (Gash and Panchamia 2013 p.3). These contractual mechanisms are the hall mark of the 'marketisation' of the public sector and through the competitive bid process for the new CRC contracts TR has opened up 'service provision to competition' across both ‘corporate (for profit) and voluntary (not for profit) providers' (Clarke 2000 p. 3). Different governments since the mid 1980's have insisted that the restructuring of public services, to conform to a more business-based model, will provide greater 'value for money' (MOJ 2013; Gash and Panchamia 2013; Fitzgibbon and Lea, 2014) and, thus, more effectiveness and efficiency. Efficiency and effectiveness imply a focus on the relationships between inputs, outputs and outcomes' (European Commission, 2008 p.2) and I will be only one of many social science researchers whose research findings show clearly that this kind of business model is not an appropriate means of evaluating the quality of services that are structured to meet the needs of vulnerable groups and individuals (Hough, 2010, pp. 158 - 159). The terms 'outputs' and 'performance' imply that the processes of rehabilitation and desistance from re-offending can be measured or quantified, but this reductionist approach belies the complexity and multi-faceted nature of the welfare needs of this vulnerable cohort of service users. Gash and Panchamia (2013) discuss the complications that arise when trying to measure value added by multi agency providers, 
such as the health service, because it is 'difficult to assess whether the outcome was generated by the provider, would have happened anyway or was generated by the actions of other service providers' (ibid. p.6). This suggests that the ways in which the new CRCs will be accountable for their services of rehabilitation for ex-offenders may become problematic. They will be in the process of commissioning the services of different community-based support services to provide rehabilitation services to reduce the reoffending rate of their clients, many of whom will have physical and mental health difficulties (such as drug and alcohol dependence). These factors of need make it difficult for many offenders to conform to the day to day requirements of resettlement after their release from prison, as was the case with the only client who was referred to Arooj who relapsed into drug taking soon after his release from prison without making any contact with Arooj mentors. Many ex-offenders follow mental health, drugs and/or alcohol treatment and other support programmes on the inside, which they may continue with after their release. Therefore there will often be a range of different agencies involved in the overall rehabilitation of ex-offenders in the community. The work of these agencies will be at an additional cost to the CRCs and this will make it difficult for them to assess the successes and failures of the different programmes and to account for how they attribute service outcomes to which provider. Dispensing with these additional agencies' services might prove an attractive option to the CRCs as a means of cutting costs, which would mean the smaller, local community TSOs going out of existence unless they can access alternative streams of funding for support.

\section{Reflections.}

The outcomes of our efforts to carry out an evaluation of ReachingOut are the result of a very small-scale, regionally-based project and therefore cannot provide the basis for any general assertions about the impact of the TR agenda nationally. However, the fact that this evaluation was thwarted by factors linked directly to the new TR arrangements will have a profound impact on Arooj's future work as a TSO and whether they choose to continue as service providers in their 
support of the rehabilitation of BAME and Muslim offenders. How and where their expertise in this area develops will depend on the direction they choose to take in response to these outcomes.

This project began at the very moment several different components of the new TR arrangements converged and heralded the unprecedented changes to probation supervision that have been discussed critically in this paper. The coincidence of these events conspired to prevent the collection of primary data with which to evaluate Arooj's three stage model.

The outcomes of our attempt to evaluate the ReachingOut programme indicate clearly that the future of the rehabilitation of low-medium risk offenders under the TR arrangements is dangerously poised in these early days, because of the cutbacks being made by the CRCs, which include redundancies of offender managers and the termination of existing contracts with the smaller TSOs. The erosion of the role of small third sector organisations in this new landscape is probably inevitable and will very likely presage the end of the road for many who will simply not be able to continue with their work if the CRCs choose to offer contracts to only the larger, national charities and social enterprise organisations.

\section{Afterword.}

Arooj has been invited, from September 2015, to be one of 14 senior experts recruited from the voluntary sector working in Criminal Justice to form a leadership forum, the Reducing Reoffending Third Sector Advisory Group (RR3). This expert advisory group has been convened with the purpose of building a strong and effective partnership between the voluntary sector, the Ministry of Justice (MoJ), and the National Offender Management Service (NOMS) in order to reduce reoffending. This acknowledgement of Arooj's work in the CJS and their support of BAME and Muslim offenders, whilst very welcome at a time when TSO's are experiencing uncertainty about their future role (if any)-in the new world of TR and CRCs, sits uncomfortably with the negative-eutcomes experiences of the ReachingOut project that have been the focus of this paper 


\section{References}

Annison, J., Burke, L., Senior, P. (2014) 'Transforming Rehabilitation: Another example of English 'exceptionalism' or a blueprint for the rest of Europe'? European Journal of Probation Vol $6(1) 6-23$.

Arooj (2014) Reducing offending within BAME and Muslim communities. A research report. (unpublished and available on request).

Brown, L. Mikel and Gilligan, C. (1991) Listening for voices in narratives of relationship. In Tappan, M.and Packer, M. New Directions for Child Development. San Fransisco:JosseyBass.

Burke, L. (2012) 'Pause for Thought'? Probation Journal Vol 59 (4): 317 - 322

Calverley, A. (20143) Cultures of Desistance. Rehabilitation, reintegration and ethnic minorities. Oxon: Routledge.

Clarke J., Gerwitz, S., McLaughlin, E. (2000) (eds) New Managerialism New Welfare? Published in association with the Open University

Clinks (2015) Early Doors: The Voluntary Sector's Role in Transforming Rehabilitation London:Clinks. Also available on line at: http://www.clinks.org/resources-reports/earlydoors-voluntary-sector\%E2\%80\%99s-role-transforming-rehabilitation Last accessed: $29^{\text {th }}$ October 2014

Corcoran, M. and Hucklesbury, A. (2012) The Third Sector in Criminal Justice University of Leeds. Available at: http://www.law.leeds.ac.uk/assets/files/research/ccjs/130703-thirdseccrimjust-briefing-2013.pdf. Last accessed 25 ${ }^{\text {th }}$ August 2015. 
Fitzgibbon and Lea (2014) 'Defending Probation: Beyond privatisation and security' European Journal of Probation Vol 6 (1) 24 - 41

Frazer et al (2014) 'Rehabilitation: What does good look like anyway'? European Journal of Probation Vol 6(2) $92-111$

Gash and Panchamia (2013) When to contract: Which service features affect the ease of government contracting? Institute for Government Working Paper. Available at: http://www.instituteforgovernment.org.uk/publications/when-contract. Last accessed $9^{\text {th }}$ October 2015.

Glaser and Strauss 2007, (2 ${ }^{\text {nd }}$ edition). The Discovery of Grounded Theory. Strategies for Qualitative Research USA: Aldene Transaction

Hamel, G., Prahalad, C. K. (1993)' Strategy as stretch and leverage' Harvard Business Review 71(2):75-84)

Her Majesty’s Government (2014) Offender Rehabilitation Act Norwich: TSO

Her Majesty's Government (2015) HM Chief Inspector of Prisons for England and Wales Annual Report 2014-15 Avaliable at: www.justiceinspectorates.gov.uk/hmiprisons. Accessed July $16^{\text {th }} 2015$.

Hough, C. V. (2010) The author's PhD thesis, Every Child Matters: a small scale enquiry into policy and practice submitted in June 2010 to the Universities of Lancaster and Cumbria. Available on request to the author.

Jabbbar, H. (2014) 'The case of 'payment-by-results': re-examining the effects of an incentive programme in nineteenth-century English schools' Journal of Educational Administration and History 45:3, 220-243 
Kiegelmann, M., (2009) 'Making Oneself Vulnerable to Discovery'. Forum: Qualitative Social Research, Volume 10, No. 2. Article 3.

King, S. (2013) 'Assisted Desistance and experiences of probation supervision' Probation Journal Vol $6(2) 136-151$

Lavalette, M. and Pratt, A (eds.) (2006) Social Policy, Theories, Concepts and Issues. London: Sage

Lawrence, I. (2015) 'Napo General Secretary sets out probation members' post-TR position in stark terms' Transforming Rehabilitation: Making it Work. Derby October $20^{\text {th }} 2015$. Available at: https://www.napo.org.uk/news/napo-general-secretary-sets-out-probation-members-post-trposition-stark-terms Accessed: 30 November 2015)

Ludlow A. (2014) 'Transforming Rehabilitation: What lessons might be learned from prison privatisation'? European Journal of Probation Vol 6(1) 76-81

Mahmood, T. and Mohammad, H, (2014) Reducing Offending in Southern Asian and Muslim Communities, Arooj. (Available from author on request).

Ministry of Justice (2013a) Transforming Rehabilitation: A revolution in the way we manage offenders. Norwich: TSO.

Minstry of Justice (2013b) Rehabilitation Programme Market Engagement, May 2013, Payment Mechanism - Straw Man. Available online at: http://webarchive.nationalarchives.gov.uk/20130128112038/http://www.justice.gov.uk/transf orming-rehabilitation/prior-information-notice. Last accessed October 12th 2015.

Minstry of Justice (2013c) Transforming Rehabilitation A Strategy for Reform Response to Consultation CP(R)16/2013 May 2013 Norwich:TSO 
Mullen, J., Clinks, BTEG and Barrow Cadbury (2014) The Young Review: Improving outcomes for young black and/or Muslim men in the Criminal Justice System. Available on line at: http://www.youngreview.org.uk/ Last accessed: $9^{\text {th }}$ October 2015

National Offender Management Service (2014). Business Plan 2014 - 2015 London: NOMS.

Prison Reform Trust (2015) Bromley Briefings Prison the Facts Summer 2015. London: Prison Reform Trust.

Ribbens, J. and Edwards, R. (1998) Feminist dilemmas in qualitative research : public knowledge and private lives. London: Sage 